\title{
A method suitable for comprehensive assessment of wind power penetration capability of regional power grids including multiple wind farms
}

\author{
S.Q. Wang, C.Z. Tian, L. Wang \\ State Grid Henan Economic Research Institute, \\ Zhengzhou, China
}

\begin{abstract}
This paper proposes a comprehensive assessment method of wind power penetration capability for multiple points of connection of wind farms, considering peak load regulation, static security, static voltage stability and transient stability constraints of power system. A mathematical model of the comprehensive assessment method is built, and the calculation process of the wind power penetration capability for multiple points of connection is designed. An actual regional power grid in a province is taken as an example to proven the validity of the proposed method.
\end{abstract}

Keywords: wind power penetration capability; comprehensive assessment method; multiple wind farms; peak load regulation; static security.

\section{INTRODUCTION}

Research on wind power penetration capability attaches great significance: on the one hand, the wind power resources can be fully developed; on the other hand, excessive scale of the wind power capacity can be avoided.

The wind farm penetration capability is mainly constrained by the system peak load regulation ${ }^{[1,2]}$, the static security ${ }^{[3,4]}$, the static voltage stability ${ }^{[5]}$ and the system transient stability ${ }^{[6,7]}$. The characteristics of the main constraints are as follows. The peak load regulation constraint is only related with the structure of power sources, load characteristics and the interregional tie-line power adjustment ability, regardless of the specific points of connection. While the other three constraints is related to the specific points of connection, of which the static security and system transient stability constraint are mainly used as means of verification for determined wind farm capacity at each points of connection. Generally, the points of connection of wind farms are chosen considering the positions of the wind power resources. When multiple points of connection of wind farms are within a regional grid, the maximum wind power penetration capability of the each points of connection influences each other ${ }^{[8]}$.

This paper proposes a comprehensive assessment method of the wind power penetration capability of multiple grid-connected wind farms. Firstly, the mathematical model of a regional grid's wind power penetration capability is given. Secondly, the

\author{
L.Y. Li, L.Q. Zou \\ State Key Laboratory of Alternate Electrical Power \\ System with Renewable Energy Sources \\ NCEPU, Beijing, China
}

calculation process is designed to assess the wind power penetration capability of multiple grid-connected wind farms. Finally, a regional grid is used as an example to validate the effectiveness of this proposed method.

\section{THE COMPREHENSIVE ASSESSMENT METHOD OF THE WIND POWER PENETRATION CAPABILITY}

\section{A. The mathematical model}

The regional maximum wind power penetration capability is $S_{\text {wind }}$,

$$
S_{\text {wind }}=\sum_{i=1}^{N_{w}} S_{\text {windi }}
$$

In (1), $S_{\text {windi }}$ is the capacity of wind farm $i, N_{w}$ is the set of wind farms.

Constraints are as follows:

$$
\begin{aligned}
& \text { S.t. }\left\{\begin{array}{l}
P_{z i}+P_{\text {windi }}-P_{L i}-U \sum_{j=1}^{N_{S}} U_{j}\left(G_{i j} \cos \theta_{i j}+B_{i j} \sin \theta_{i j}\right)=0 \quad i \in N_{S} \\
Q_{g i}+Q_{\text {windi }}-Q_{L i}-U_{i} \sum_{j=1}^{N_{S}} U_{j}\left(G_{i j} \sin \theta_{i j}-B_{i j} \cos \theta_{i j}\right)=0 \quad i \in N_{S}
\end{array}\right. \\
& \left\{\begin{array}{l}
S_{\text {windi }} \leq S_{\text {resourcei }}, i \in N_{w} \\
S_{\text {wind }} \leq S_{\text {peak }} \\
0 \leq P_{l i} \leq P_{l \max }, i \in N_{l} \\
P_{g i \min } \leq P_{g i} \leq P_{g i \max }, i \in N_{g} \\
U_{i \min } \leq U_{i} \leq U_{i \max }, i \in N_{s}, 0 \leq P_{w j} \leq S_{\text {windj }}\left(j \in N_{w}\right) \\
I_{s i}<I_{S N}, i \in N_{s}
\end{array}\right.
\end{aligned}
$$

Equation(2) is the power flow equality constraint, in which, $\mathrm{N}_{S}$ is the set of all nodes, $\mathrm{P}_{g i}$ and $\mathrm{Q}_{g i}$ are the injected real and reactive power into node $i, \mathrm{P}_{\text {windi }}$ and $\mathrm{Q}_{\text {windi }}$ are the injected real and reactive power into the wind farm $i, \mathrm{P}_{L i}$ and $\mathrm{Q}_{L i}$ are the real and reactive power of the load at node $i, \mathrm{U}_{i}$ and $\mathrm{U}_{j}$ are the voltages of node $i$ and $j$ respectively, $\mathrm{G}_{i j}$ and $\mathrm{B}_{i j}$ are the real and imaginary parts of the admittance of branch $i-j, \theta_{\mathrm{ij}}$ is the phase angle difference of branch $i-j$. 
Equation(3) are the inequality constraints, in which, $\mathrm{S}_{\text {resourcei }}$ is the available capacity of the wind farm $i$, $\mathrm{N}_{w}, \mathrm{~N}_{1}, \mathrm{~N}_{\mathrm{g}}, \mathrm{N}_{\mathrm{s}}$ are the sets of the wind farms, branches, nodes of the generators and the total nodes respectively, $S_{\text {peak }}$ is the maximum wind power penetration capability considering peak load regulation constraint, $\mathrm{P}_{g i \max }$ and $\mathrm{P}_{g i \text { min }}$ are the upper and lower real power limits of generator $i, \mathrm{U}_{\mathrm{i} \max }$ and $\mathrm{U}_{\mathrm{i} \text { min }}$ are the upper and lower voltage limits of node $i, I_{s i}$ and $I_{S N}$ are the short circuit current of node $i$ and the related breaker capacity respectively. follows:

The above considered inequality constraints are as

1) The capacity of a wind farm is smaller than its resource capacity (available wind power capacity at the point of connection).

2) The sum of all wind farm capacity is smaller than the maximum wind power penetration capability constrained by peak load regulation.

3) Static security constraints: the power constraints of the transmission lines, the power constraints of generators.

4) With the change of the wind farm output, the voltages of the monitoring nodes are not beyond the limits.

5) The level of the system short circuit is not exceeded with the integration of certain wind power capacity, and system transient stability should be kept in case of failures.

\section{B. The calculation process}

The overall train of thought to assess the wind power penetration capability in a region is about three steps. Firstly, calculate the wind power penetration capability based on the peak load regulation constraint. Secondly, compute the wind power capacity of the different grid-connected points based on static security and static voltage stability constraints. Lastly, verify the wind power penetration capability by system transient stability constraint. The flow path of the calculation is shown as Fig.1.

The specific calculating process is as follows:

1) Calculate the max wind power penetration capability $S_{\text {peak }}$ based on peak load regulation constraint [9-10].

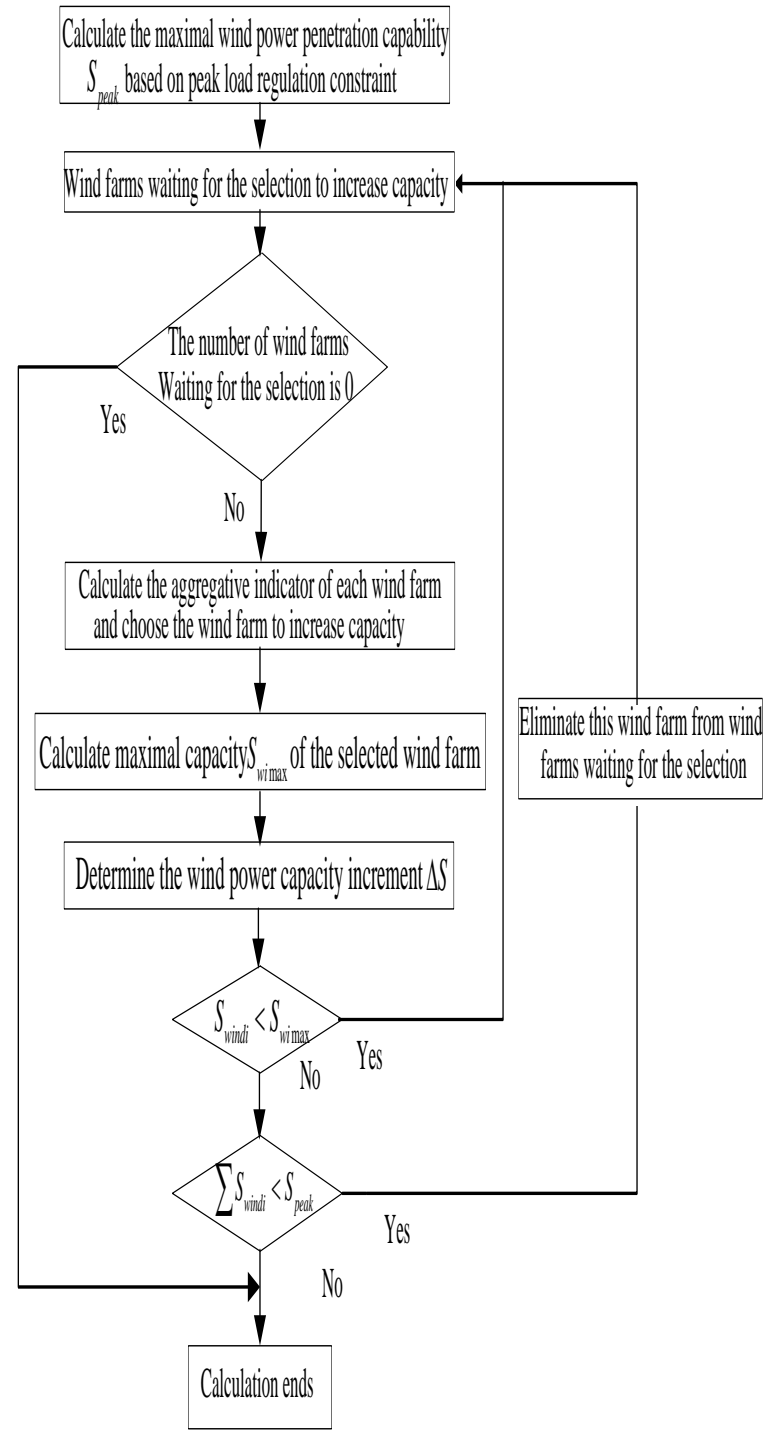

Figure 1. Flow path of calculating the wind power penetration capability of multiple wind farms.

2) Select the wind farm to increase the capability. The wind farm $i$ is selected by the optimization aggregative indicator as (4).

$$
\begin{gathered}
\lambda_{i}=-\alpha_{1} \Delta Q_{i}+\alpha_{2} P_{l s i}+\alpha_{3} P_{\text {resourcei }}, i \in N_{w} \\
\alpha_{1}+\alpha_{2}+\alpha_{3}=1
\end{gathered}
$$

In (4), $\Delta Q_{i}$ is the reactive power margin of the weakest node in voltage, which takes the per unit value using the system base value. A positive reactive power margin means that the system is insufficient in reactive power, so a negative sign is added before the indicator. $P_{l s i}$ equals the difference between transmission limit and the load of the out-sending line of wind farm $i$ of which the load rate is highest. It takes the per unit value with its transmission limit as the base value. $P_{\text {resourcei }}$ is the difference value between resource capacity and existing capacity of wind farm $i$, which also takes the 
per unit value using the system base value. $\alpha_{1}, \alpha_{2}, \alpha_{3}$ is the weight coefficient of each indicator. In this paper, $\alpha_{1}=0.50, \alpha_{2}=0.25, \alpha_{3}=0.25$, priority is given to the reactive power margin. The wind farm with the largest aggregative indicator is selected.

3) Considering peak load regulation, static security, static voltage stability, and s wind resource constraints in (3), calculate maximal capacity $S_{\text {wimax }}$ of the selected wind farm.

4) Determine the wind power capacity increment $\Delta S$ for the selected wind farm. The original value of $\Delta S$ is $20 \mathrm{MW}$, and the capacity of the wind farm should be less than $S_{\text {wimax }}$ subsequent to the increment, as shown in (6).

$$
\Delta S=\left\{\begin{array}{l}
20, \quad S_{i}+20 \leq S_{w i \max } \\
S_{i \max }-S_{i}, \quad S_{i}+20>S_{w i \max }
\end{array}\right.
$$

In (6), $S_{i}$ is the capacity of wind farm before increment.

5) Judge whether the selected wind farm capacity has reached the maximum, if not, repeat $(b)-(d)$ steps. Otherwise, judge the reason for the maximum. If the reason is peak load regulation constraint, the computing process ends; if not, remove the wind farm from those to be selected and repeat (b)-(d) steps. The computing process ends until the total of wind farm capacity reaches $S_{\text {peak }}$ or the number of wind farms waiting for selection is 0 .

6) Verify whether the system stability is satisfied or not with the wind farm capacity. If not, reduce the limit of the total wind farm capacity by decreasing the value of $S_{\text {peak }}$, and recalculate until the system transient stability is satisfied.

\section{CASE STUDY}

An actual regional grid is taken as an example. The maximal wind power penetration capability based on peak load regulation constraint is $1560 \mathrm{MW}$ in 2020. There are nine planned wind farms in this region, they concentrate on two areas. As shown in Fig .2, the voltage of thicker blue lines is $220 \mathrm{kV}$, the thinner green lines $110 \mathrm{kV}$

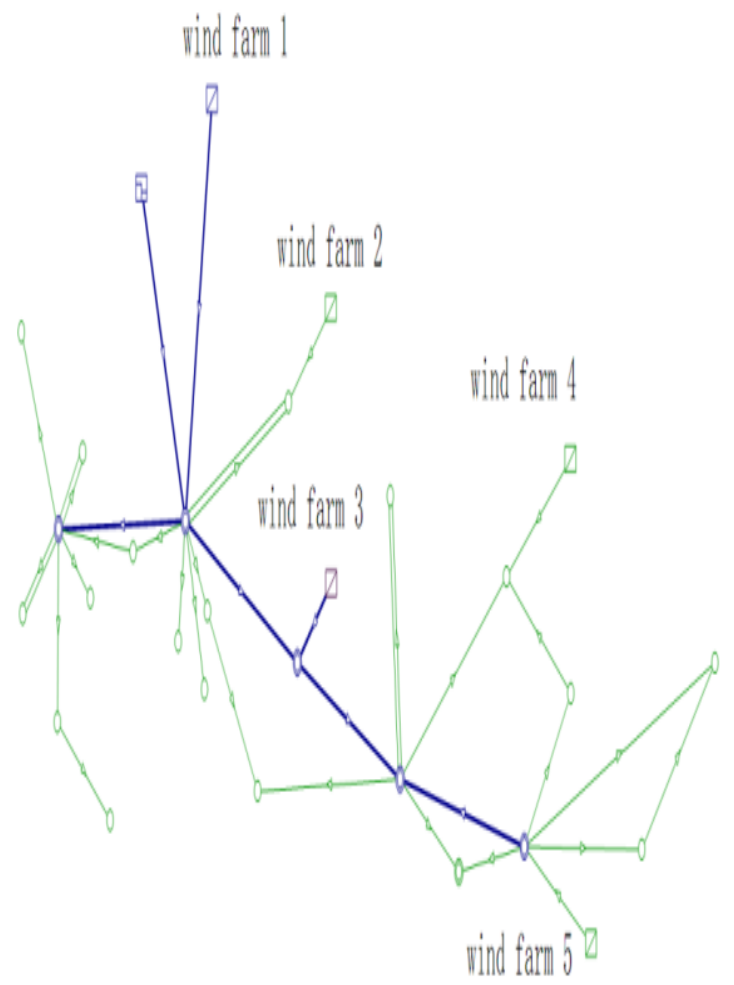

a) area 1

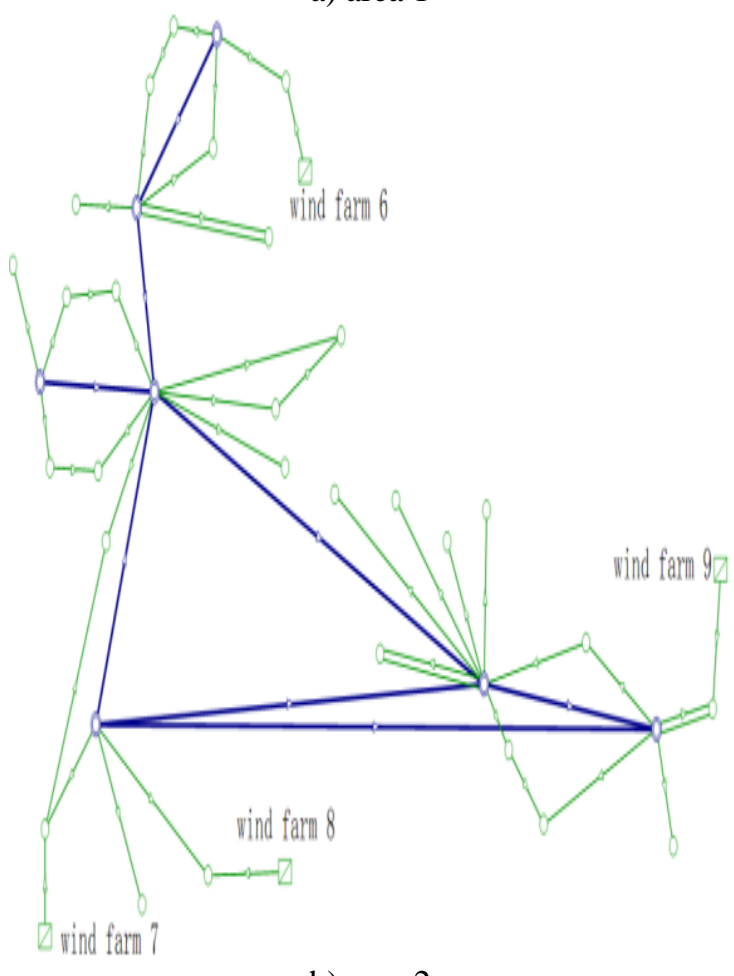

b) area 2

Figure 2. Wind farm grid-connection graph of the studied region.

With the regional power grid data model and resource capacity of each wind farm, the maximal wind power capacity of each points of connection is calculated by BPA. The calculation process is shown in TABLE I. 
TABLE I. THE CALCULATIOO PROCESS OF THE WIND POWER PENETRATION CAPABILITY OF THE STUDIED REGIONAL POWER GRID IN 2020.

\begin{tabular}{|c|c|c|c|}
\hline $\begin{array}{l}\text { calculat } \\
\text { ion } \\
\text { process }\end{array}$ & $\begin{array}{l}\text { the } \\
\text { chosen } \\
\text { wind } \\
\text { farm }\end{array}$ & $\begin{array}{l}\text { the wind farm } \\
\text { capacity after } \\
\text { increment } \\
\text { MW }\end{array}$ & $\begin{array}{l}\text { the limited } \\
\text { wind farm } \\
\text { capacity } \\
\text { condition }\end{array}$ \\
\hline 1 & $\begin{array}{l}\text { wind } \\
\text { farm } 3\end{array}$ & 20 & none \\
\hline 2 & $\begin{array}{l}\text { wind } \\
\text { farm } 1\end{array}$ & 20 & none \\
\hline 3 & $\begin{array}{l}\text { wind } \\
\text { farm } 5\end{array}$ & 20 & none \\
\hline . & $\cdot$. & $\cdot \cdot \cdot$ & $\cdot \cdot \cdot$ \\
\hline 12 & $\begin{array}{l}\text { wind } \\
\text { farm } 1\end{array}$ & 100 & none \\
\hline 13 & $\begin{array}{l}\text { wind } \\
\text { farm } 5\end{array}$ & 87 & $\begin{array}{l}\text { resource } \\
\text { capacity limit }\end{array}$ \\
\hline . & . . & $\cdot \cdot \cdot$ & $\cdot \cdot \cdot$ \\
\hline 24 & $\begin{array}{l}\text { wind } \\
\text { farm } 1\end{array}$ & 192 & $\begin{array}{l}\text { resource } \\
\text { capacity limit }\end{array}$ \\
\hline 25 & $\begin{array}{l}\text { wind } \\
\text { farm } 3\end{array}$ & 192 & $\begin{array}{l}\text { resource } \\
\text { capacity limit }\end{array}$ \\
\hline . & $\cdot$ & $\cdot \cdot \cdot$ &.$\quad \cdot$ \\
\hline 37 & $\begin{array}{l}\text { wind } \\
\text { farm } 2\end{array}$ & 99 & $\begin{array}{l}\text { resource } \\
\text { capacity limit }\end{array}$ \\
\hline 38 & $\begin{array}{l}\text { wind } \\
\text { farm } 4\end{array}$ & 144 & $\begin{array}{l}\text { resource } \\
\text { capacity limit }\end{array}$ \\
\hline . . & $\cdot$ & $\cdot \cdot \cdot$ &.$\quad \cdot$ \\
\hline 50 & $\begin{array}{l}\text { wind } \\
\text { farm } 7\end{array}$ & 120 & $\begin{array}{l}\text { surpass lower } \\
\text { voltage limit }\end{array}$ \\
\hline . &. & $\cdot \cdot \cdot$ & . . . \\
\hline 54 & $\begin{array}{l}\text { wind } \\
\text { farm } 9\end{array}$ & 80 & $\begin{array}{l}\text { surpass lower } \\
\text { voltage limit }\end{array}$ \\
\hline 55 & $\begin{array}{l}\text { wind } \\
\text { farm } 6\end{array}$ & 96 & $\begin{array}{l}\text { resource } \\
\text { capacity limit }\end{array}$ \\
\hline 56 & $\begin{array}{l}\text { wind } \\
\text { farm } 8\end{array}$ & 80 & $\begin{array}{l}\text { resource } \\
\text { capacity limit }\end{array}$ \\
\hline 57 & $\begin{array}{l}\text { wind } \\
\text { farm } 8\end{array}$ & 96 & $\begin{array}{l}\text { resource } \\
\text { capacity limit }\end{array}$ \\
\hline
\end{tabular}

Verification shows that the system stability is satisfied with the calculated wind farm capacity. Therefore, the wind power penetration capability of each wind farm from 1-9 is $192,99,192,144,87,96$, 120, 96, 80 MW respectively.

\section{CONCLUSION}

Based on the constraints of the wind power penetration capacity, this paper proposes a comprehensive assessment method for multiple wind farms. The mathematical model is built, and the realizing calculation process is designed. An aggregative indicator is used to select the wind farm to increase capacity so that the obtained wind power penetration capacity is optimal in the aspects of reactive voltage, static security and wind power capacity. The increment of wind power capacity is determined considering the peak load regulation, static security, and static voltage stability constraints to ensure the safe and stable operation of power system. The wind power penetration capacity is obtained through multiple iterations, and the system transient stability is verified to get the final acceptance of wind power capacity.

\section{REFERENCES}

[1] Ning Zhang, Tianrui Zhou, Changgang Duan, et al.. Impact of large-scale wind farm connecting with power grid on peak load regulation demand $[\mathrm{J}]$. Power System Technology, 2010, 34(1): 52-58.

[2] Zhiming Wang, Anlong Su, Shun Lu. Analysis on capacity of wind power integrated into Liaoning power grid based on power balance [J]. Automation of Electric Power Systems, 2010, 34(3): 86-90.

[3] Nick M., Riahy G.H., Hosseinian S.H., et al.. Wind power optimal capacity allocation to remote areas taking into account transmission connection requirements [J]. IET Renewable Power Generation, 2011, 5(5): 347-355.

[4] Matevosyan J.. Wind power integration in power systems with transmission bottlenecks [C]. IEEE PES General Meeting, 2007: $1-7$.

[5] Palsson M.P., Toftevaag T., Uhlen K., et al.. Large-scale wind power integration and voltage stability limits in regional networks[C]. IEEE Power Engineering Society Summer Meeting, 2002, 2: 762-769.

[6] EL-Shimy M., Badr M. A. L., RASSEM O. M. Impact of large scale wind power on power system stability [C]. 12th International Middle-East Power System Conference, 2008: 630-636.

[7] Meegahapola L., Flynn D.. Impact on transient and frequency stability for a power system at very high wind penetration [C] PES General Meeting, 2010: 1-8.

[8] Bakhtvar M., Keane, A.. Optimal allocation of wind generation subject to voltage stability constraints [C]. 4th IEEE PES General Meeting, 2013: 1-5

[9] Dezhi Chen, Ming Dai. The research on the influence of largescale wind power connected to shanxi power grid peak shaving [J]. East China Electric Power, 2011, 39(8): 1257-1261.

[10] Henriklund . Renewable energy systems: the choice and modeling of $100 \%$ renewable solutions[M]. Burlington, USA : Academic Press, 2009 